\title{
Consulta indígena de concesiones mineras. Comentario de jurisprudencia
}

\section{Indigenous consultation of mining concessions. Case law commentary}

Francisco Salmona Maureira*

En este trabajo se analiza la pertinencia de la consulta indígena en el procedimiento concesional minero. La jurisprudencia que se comenta entiende que no es necesaria esa consulta, por tratarse de resoluciones judiciales que escapan de su alcance. En este comentario argumentamos que las concesiones mineras son actos administrativos que podrían requerir de una consulta indígena previa a su dictación, en la medida que impliquen una afectación de los pueblos indígenas.

Palabras clave: Concesiones mineras, Consulta indígena, Convenio 169 OIT.
This paper examines the pertinence of the indigenous consultation in the procedure for the constitution of mining concessions. The case commented holds that the consultation is not necessary, as judicial decisions scape their scope. In this commentary we argue that mining concessions are administrative decisions that may require indigenous consultation prior to their dictation, if they affect the interests of indigenous peoples.

Keywords: Mining concessions, Indigenous consultation, ILO Convention 169.

\section{Introducción}

El presente trabajo constituye a un comentario jurisprudencial referente al objeto de la consulta indígena que se recoge en el Convenio $N^{\circ} 169$ de la Organización Internacional del Trabajo (Convenio), en relación con el aprovechamiento de los recursos mineros. Específicamente, se refiere a la pregunta acerca si es procedente dicha consulta respecto de la

\footnotetext{
* Profesor LLM UC Pontificia Universidad Católica de Chile, Santiago, Chile. Master of Laws (LLM) por la Universidad de Nueva York, Magister en derecho público, mención en derecho constitucional por la Pontificia Universidad Católica de Chile y Licenciado en Derecho por esa última Universidad. Correo electrónico: fsalmona@uc.cl. Dirección postal: Málaga 339, Las Condes, Santiago de Chile.
}

Artículo recibido el 18 de febrero de 2021 y aceptado el 28 de mayo de 2021. 
constitución de derechos mineros (concesiones mineras de exploración o explotación) sobre sustancias concesibles, por medio del procedimiento judicial establecido en el Código de Minería (CM).

La Corte de Apelaciones de Valdivia, en sentencia dictada con fecha 23 de abril de 2015, respondió la pregunta de manera negativa ${ }^{1}$. La Corte Suprema, un mes más tarde, confirmó el criterio de la Corte de Valdivia ${ }^{2}$. El argumento es simple y directo: se trata de resoluciones judiciales, no actos legislativos o administrativos. Los actos jurisdiccionales quedarían excluidos de la misma.

De otro lado, la doctrina científica ha manifestado que, de conformidad al estándar internacional, el Gobierno debe consultar a los pueblos indígenas interesados antes de constituir tales concesiones mineras. En este sentido, algunos abogan por que se realicen las modificaciones correspondientes a nivel legal que hagan posible dicha consulta ${ }^{3}$. Otros, por su parte, argumentan una aplicación directa de las normas del Convenio en el orden interno, de manera tal que, al ser inmediatamente exigibles, ordenan a los operadores jurídicos -en este caso el juez- a adecuar el proceso y realizar un proceso de consulta ${ }^{4}$. A nivel institucional, el Comité de Expertos OIT -órgano de control de los estándares internacionales de dicho organismo-, ha manifestado al Estado de Chile su deber de reformar el régimen de concesiones contenido en el CM para cumplir a cabalidad con las disposiciones del Convenio ${ }^{5}$.

Por nuestra parte, consideramos que las concesiones mineras son actos administrativos $y$, en consecuencia, requerirán de una consulta indígena previa a su dictación, en la medida que impliquen una afectación directa de los pueblos indígenas interesados. Con todo, el actual procedimiento concesional minero regulado en el CM no admite la posibilidad que el juez pueda ordenar el desarrollo de una consulta; de lo que aparece la conveniencia de una reforma legal en esta materia.

Nos referiremos primero a la doctrina emanada de la sentencia en comento para, después, desarrollar un breve comentario que recoja el sustento de la tesis antes mencionada.

\footnotetext{
1 Corte de Apelaciones de Valdivia Rol No 1.091-2014.

2 Corte Suprema Rol N 6.303-2015.

3 Esta es la posición, por ejemplo, de Hervé y Pérez 2012, 15 y ss. (sugiriendo una compatibilización entre el régimen de aprovechamiento establecido en la actual legislación minera y las normas de protección de intereses indígenas; 85-86; conclusión $\mathrm{N}^{\circ}$ 9, en 100). También de BARROS Y SCHÖNSTEINER 2014 (quienes entienden que el actual régimen de otorgamiento de concesiones mineras cae por debajo del estándar internacional de consulta, y recomiendan dar prioridad a la adecuación de los estándares internacionales de la regulación de la consulta e inversiones, especialmente, entre otras materias, respecto de concesiones mineras; recomendación $N^{\circ} 2$ al Estado, 244).

4 Es la posición, según entendemos, de Yáñez 2012 (al comentar el trabajo de Hervé y Pérez referido en la cita anterior, 102-109); también de CARMONA 2019.
}

${ }^{5}$ OIT 2013. 


\section{La doctrina emanada de la sentencia: La concesión minera no es consultable}

\section{El recurso de protección}

Comunidades indígenas interpusieron un recurso de protección ante la Corte de Apelaciones de Valdivia. El recurso fue deducido en contra de Jueces de Letras de la ciudad de Osorno y del Estado de Chile, con la finalidad que se declarase por la Corte la nulidad de sentencias firmes de los Juzgados de Letras recurridos, que constituyeron concesiones mineras sobre -según indican los recurrentes- territorios pertenecientes a las comunidades indígenas recurrentes.

La nulidad sería procedente -en concepto de los recurrentes- por no haber realizado una consulta indígena en forma previa a la dictación de la sentencia constitutiva de las concesiones mineras, incumpliéndose por los jueces el deber de consulta previa a que se refiere el art. 6(1)(a), del Convenio ${ }^{6}$. Por tal omisión ilegal se amenaza y/o priva a los recurrentes de las garantías que se les reconoce en los Nos 1, 3, 4, 5, 6, 8 y 24 de la Constitución. Para sustentar la procedencia de la consulta indígena del art. 6(1)(a) del Convenio, se argumentó que la sentencia constitutiva de una concesión minera debe entenderse como una medida de carácter legislativo, por cuanto es característica de toda sentencia definitiva que resuelve un juicio o solicitud presentada ante un Tribunal de Justicia, constituir la "materialización máxima de la ley".

\section{La sentencia de la Corte de Apelaciones}

Por sentencia de fecha 23 de abril de 2015, la Corte de Apelaciones de Valdivia rechazó el recurso en todas sus partes. La Corte desarrolla básicamente dos argumentos: (i) uno sustantivo, referente a la improcedencia de la consulta indígena en cuanto la sentencia constitutiva de una concesión minera constituye una resolución judicial, y; (ii) otro procesal, consistente en la improcedencia del recurso de protección como vía idónea para cuestionar resoluciones judiciales.

En primer lugar, la Corte razona que el art. 6(1)(a) del Convenio obliga a consultar únicamente las medidas legislativas y administrativas. De igual manera, el Reglamento para la implementación de la consulta del art. 6 del Convenio, Decreto Supremo N 66/2013, Ministerio de Desarrollo Social (Decreto N 66/2013), se aplica a los órganos de la Administración del Estado y, según su propia definición, únicamente a los ministerios, intendencias, gobiernos regionales, las gobernaciones y los servicios públicos creados por ley para el cumplimiento de la función administrativa ${ }^{7}$. Esta definición del reglamento, además de tener una función normativa - determina qué materias deben ser

\footnotetext{
6 El recurso también hace referencia a la consulta del art. 15 del Convenio, pero reconoce que el Tribunal Constitucional declaró como autoejecutable únicamente aquella del art. 6(1)(a), citando al efecto las sentencias Rol No 309 y 1.050 de dicho tribunal. Vid. escrito de recurso de protección, 7.

7 Corte de Apelaciones de Valdivia Rol N 1.091-2014, cons. $4^{\circ}$.
} 
consultadas y por quienes-, constituye, para la Corte, una interpretación del Convenio ${ }^{8}$.

La función jurisdiccional llevada a cabo por los Tribunales de Justicia -desarrolla posteriormente la Corte- no es parte, ni se identifica, con la función legislativa. Esto deviene de su sentido natural y obvio, puesto que la voz legislativa se refiere a la potestad de hacer leyes, mientras que la función jurisdiccional a la de aplicar las mismas a un caso concreto"; se hubiere querido incluir dentro del objeto de la consulta también a los actos de los Tribunales de Justicia, ello se habría hecho expresamente. De esta forma, el hecho que el texto del Convenio y el reglamento omitieran a los actos del Poder Judicial, demuestra la intención o ánimo de excluirlos ${ }^{10}$.

En segundo término, la Corte afirma que el recurso de protección no es un medio idóneo para discutir sobre la validez o nulidad de las sentencias definitivas que otorgan concesiones mineras, las que, por su naturaleza de resoluciones judiciales, tienen previsto su propio régimen de impugnación ${ }^{11}$.

De esta manera, el tribunal niega la existencia de un acto arbitrario o ilegal, no siendo necesario analizar las garantías constitucionales que se dicen conculcadas, rechazando el recurso.

\section{Comentario}

Interesa en este trabajo referirnos al argumento sustantivo avanzado por la Corte, proponiendo un entendimiento diverso del problema.

1. ¿Qué debe consultarse? El estándar respecto del objeto de la consulta de los pueblos indígenas

El deber de consulta de los pueblos indígenas constituye una norma de derecho internacional que establece un derecho colectivo a favor de dichos pueblos. Las fuentes de este deber/derecho son variadas ${ }^{12}$. En lo que interesa a nuestro análisis, el art. 6(1)(a) del Convenio dispone que deben ser consultados los pueblos indígenas interesados, cada vez que se prevean medidas legislativas o administrativas susceptibles de afectarles directamente. La medida legislativa o administrativa que se prevea constituye, entonces, el objeto de la consulta. Necesario es notar que el Convenio posee varias instancias

\footnotetext{
8 idem.

9 lbíd., cons. $5^{\circ}$.

10 Ibíd., cons. $5^{\circ}$

11 Ibíd., cons. $7^{\circ}$.

12 El deber de consulta se encuentra establecido en una norma convencional. También lo está en la Declaración de Naciones Unidas sobre los derechos de los pueblos indígenas de 2007. Consta además de las decisiones de tribunales internacional, como es el caso de la Corte Interamericana de Derechos Humanos. Vid. Kichwa Peoples of the Sarayaku community and its members v. Ecuador. Incluso, un deber de consulta ha emanado de organizaciones internacionales de carácter público, como es el BANCo Mundial (2005); el IFC (2012), o privados, como es el caso de ICMM (2013).
} 
en las cuales se genera un deber de consultar a los pueblos indígenas, en las que se especifica el objeto u medida a consultar, como también se califica el estándar de consulta (una finalidad específica o, en algunos casos, el consentimiento previo, libre e informado) ${ }^{13}$.

Particularmente, respecto de circunstancias que se relacionen con sus tierras, territorios y los recursos naturales que se encuentran en ellos, el art. 15(2) del instrumento internacional dispone que, en caso que pertenezcan al Estado la propiedad de los minerales, recursos del subsuelo o tenga el Estado derechos sobre otros recursos existentes en las tierras indígenas, el Estado deberá establecer o mantener procedimientos con miras a consultar a los pueblos interesados, a fin de determinar si los intereses de dichos pueblos serían perjudicados, y en qué medida, antes de emprender o autorizar cualquier programa de prospección o explotación de los recursos existentes en sus tierras ${ }^{14-15}$.

El objeto de la consulta del art. 15(2) del Convenio difiere, en parte, de aquella regulada en el art. 6(1)(a). En el primer caso se evidencia un mayor contenido preventivo, al tener la consulta la finalidad de determinar si los intereses indígenas pueden o no ser perjudicados, antes de la autorización de las primeras fases de desarrollo de un proyecto minero, esto es, de su exploración. Se habilita con ello el ejercicio de los demás derechos contemplados en la misma norma, esto es, el derecho al beneficio compartido de las ganancias, como el de ser indemnizados por los daños que el proyecto les produzca ${ }^{16}$.

${ }_{13}$ El Convenio requiere la consulta de los pueblos indígenas en el caso de relocalización, art. 16(2); en caso que se considere su capacidad de enajenar sus tierras o de transmitir de otra forma sus derechos sobre sus tierras fuera de su comunidad, art. 17(2); sobre programas especiales de formación, art. 22(3); respecto de medidas que permitan alcanzar el objetivo que niños de los pueblos interesados puedan ser enseñados a leer y escribir en una lengua indígena, art. 28(1). El Convenio solo requiere el consentimiento previo, libre e informado para el caso de la relocalización del art. 16. En los demás casos, solo es necesario una consulta, con el objetivo que cada una de dichas normas indica.

14 Útil es mencionar que el Convenio se refiere, en este punto, a las "tierras", lo que, de conformidad al art. 13(2) del instrumento, incluye también los "territorios", lo que cubre la totalidad del hábitat de las regiones que los pueblos interesados ocupan o utilizan de alguna u otra manera. Por otro lado, si bien técnicamente puede establecerse una diferencia entre las actividades de "exploración" y de "prospección", al partir de su tenor literal, parece que no es el sentido del Convenio distinguir entre una y otra. Es más, la OIT utiliza una y otra expresión de manera intercambiable, OIT 2009, 107-108.

15 Como derechos adicionales de los pueblos indígenas, el Convenio contempla el derecho a beneficiarse de las ganancias que reporten la expropiación y uso de los recursos naturales, como el derecho a recibir una indemnización por los daños causados por la prospección y explotación de los recursos naturales (art. 15(2)). Por la naturaleza de este trabajo, no nos referiremos a ellos.

16 Ahora bien, teniendo en cuenta que los proyectos de exploración o explotación de los recursos pueden tener un largo tiempo de desarrollo, la OIT entiende que el art. 15 debe leerse en conjunto con los artículos 6 y 7(3) del Convenio, de manera que un mismo proyecto pueda tener, durante toda su extensión de tiempo, distintos procesos de consulta y participación de los indígenas respectos de los impactos del proyecto en sus intereses, más allá que la sola evaluación de la decisión de llevar a cabo la exploración o explotación. OIT 2009, 108. 
La Declaración de Naciones Unidas posee enunciados paralelos al Convenio, aunque relativamente más amplios, pero que pueden ayudar como guía al intérprete ${ }^{17}$. En primer lugar, el art. 19 de la Declaración, haciendo espejo de la norma contenida en el art. 6(1)(a) del Convenio, obliga a consultar las medidas legislativas o administrativas que afecten ${ }^{18}$ a los pueblos indígenas. Ambos cuerpos poseen un objeto de consulta similar; difieren, sin embargo, en cuanto a su estándar de cumplimiento: la Declaración requiere que la consulta sea practicada para obtener de los indígenas un consentimiento "libre, previo e informado".

La Declaración también contiene en su art. 32(2) una obligación de consulta respecto de la aprobación de cualquier proyecto que afecte sus tierras, territorios u otros recursos, particularmente en relación con el desarrollo, la utilización o explotación de recursos minerales, hídricos o de otro tipo. Y esa consulta posee una distinta finalidad a la del Convenio, pues exige que la intervención en los recursos de propiedad indígena cuente con el consentimiento "previo, libre e informado" por parte de los pueblos consultados.

Nótese, además, que el art. 26(1) de la Declaración reconoce a los pueblos indígenas un derecho directo a los recursos que tradicionalmente han poseído, ocupado, utilizado o adquirido, sin una distinción expresa por los sistemas en que el dueño de los recursos minerales es el Estado. Sin embargo, entendemos que una reserva de dominio de los recursos minerales en favor del Estado puede ser compatible con esta disposición.

En síntesis, lo que se consulta son (i) las medidas legislativas o administrativas, en cuanto (ii) afecten -directamente, como califica el Convenio-, los intereses de pueblos indígenas. Ahora, cuando se trate de la exploración o explotación de recursos minerales sobre los cuales el Estado retiene su propiedad, recursos del subsuelo, u otros recursos naturales ubicados en tierras indígenas sobre los cuales el Estado tenga derecho, el Convenio contiene un régimen de consulta especial, cuyo objeto serán las (i) medidas que aprueben los programas de exploración -prospección, en palabras del Conveniou explotación (ii) a fin de determinar si los intereses de dichos pueblos serían perjudicados.

\footnotetext{
17 Ha sido tradicional que se le reste fuerza vinculante a la Declaración, por cuanto una Declaración de la Asamblea General de las Naciones Unidas no tiene la misma fuerza obligatoria que un tratado internacional. Con todo, algunos han argumentado por una mayor implementación de los derechos contenidos en ella, vid. STAVenhagen 2009. Otros, por su parte, han visto la posibilidad de usarla como fuente de interpretación de otros tratados, particularmente, del Convenio; vid. en este sentido, Kingsbury 2011 (argumentando la influencia de la Declaración en la interpretación de tratados internacionales como es el Convenio. En su concepto, la Declaración puede ser aplicada, en algunos casos, como evidencia de la norma de derecho internacional aplicable, para los efectos de regla de interpretación del art. 31(3)(c) de la Convención de Viena sobre el derecho de los tratados. En otras situaciones, sirve como base textual en caso que otros tratados hagan referencia a ella, como es el caso de la Carta Africana sobre los derechos humanos y de los pueblos).

${ }^{18}$ Nótese que la Declaración requiere únicamente que se "afecten" los intereses indígenas, mas no que se afecten de manera "directa".
} 
A nivel nacional, con todo, la discusión acerca del alcance del deber de consulta se ha reconducido a la interpretación de la consulta del art. 6(1)(a) del Convenio. Ello ha sido así -creemos- fruto de la temprana declaración por parte del Tribunal Constitucional del art. 6 del Convenio como una norma autoejecutable, mientras que otras disposiciones del Convenio, como es aquella del art. 15, fueron calificadas de programáticas ${ }^{19}$. Aunque la distinción puede ser cuestionada, éste ha sido el punto de partida para el análisis de las disposiciones de consulta, estimándose que la aplicación del resto de las disposiciones del Convenio requiere la adecuación del ordenamiento interno ${ }^{20}$.

El deber de consulta -del art. 6 del Convenio- se implementó a nivel reglamentario por el Decreto $N^{\circ}$ 66/2013, y también se incluyeron normas especiales de consulta en el reglamento del Sistema de Evaluación de Impacto Ambiental, Decreto Supremo No 40/2013, Ministerio de Medio Ambiente. En ambos, el objeto de la consulta -arts. 7 y 85, respectivamente- corresponden a las medidas legislativas o administrativas que puedan afectar directamente a los pueblos indígenas.

2. El otorgamiento de un derecho minero a través de una concesión judicial no es una medida legislativa, ni tampoco un acto jurisdiccional

Nos abocaremos ahora a la naturaleza de la sentencia constitutiva de concesión minera. Recordemos que los recurrentes de protección la identificaron como una "medida legislativa". La Corte de Apelaciones de Valdivia, por su parte, como una resolución judicial propia del ejercicio de la función jurisdiccional. Pareciere que ninguno de los dos extremos es correcto.

El art. $19 N^{\circ} 24$ de la Constitución Política sienta las bases del sistema de aprovechamiento de los recursos minerales; sistema que es complementado por la Ley Orgánica Constitucional de Concesiones Mineras, Ley $N^{\circ} 18.097$ (LOCCM) y el CM. De conformidad a la disposición constitucional, el Estado tiene el dominio absoluto, exclusivo, inalienable e imprescriptible de todas las minas, lo que constituye, para la doctrina, el dominio público del Estado sobre los recursos minerales ${ }^{21}$.

\footnotetext{
19 En la conocida sentencia del año 2000, el Tribunal Constitucional planteó la distinción en los siguientes términos: "Los tratados, para su aplicación en el orden interno de un país, pueden contener dos tipos de cláusulas, denominadas por la doctrina 'self executing' y 'non self executing'. Las primeras, son las que tienen el contenido y precisión necesarios que las habilita para ser aplicadas sin otro trámite como fuente del derecho interno. En otros términos, son auto suficientes, y entran a la legislación nacional cuando el tratado que las contiene se incorpora al derecho vigente. Las segundas, son aquellas que requieren para su entrada en vigencia de la dictación de leyes, reglamentos o decretos que las implementen y, en tal evento, las hagan aplicables como fuente del derecho interno. En otras palabras, imponen la obligación al Estado, para que en uso de sus potestades públicas, sancione la normativa necesaria para que por esa vía les dé vigencia efectiva". Tribunal Constitucional Rol 309-00, cons. 48.

20 Vid., Montt y Matta 2011; Hervé y Pérez 2012, 15 y ss. Para una crítica, vid. comentario de YÁÑEZ 2012, 102 y ss.

21 Para la doctrina tradicional, este dominio del Estado sobre la riqueza mineral es uno de tipo sui generis. Vid. LIRA 2013, 68. Para una crítica, vid. entre muchos otros escritos del autor en la
} 
Las sustancias minerales que tienen el carácter de concesibles -regla general en nuestro sistema-22 pueden ser aprovechadas mediante concesiones de exploración o explotación. Dichas concesiones son otorgadas por los Tribunales de Justicia, en procedimiento no contencioso ${ }^{23}$, sin intervención decisoria de otra autoridad o persona ${ }^{24}$ y a través de resoluciones judiciales. El procedimiento concesional está constituido por actos trámite rigurosos y que admiten una mínima intervención de parte de terceros ${ }^{25}$. Culmina con un acto concesional, que el CM Ilama "sentencia constitutiva"26, a partir del cual se otorgan al concesionario un haz de derechos, particularmente para explorar y/o explotar, según la naturaleza de la concesión que le ha sido otorgada.

Parece fácil -a partir del dato normativo-, descartar que la sentencia constitutiva de una concesión minera de exploración o explotación se trate de una medida legislativa. Más arduo es desentrañar si se trata (o no) del ejercicio de la función jurisdiccional.

Los textos constitucionales y legales hacen mención que la concesión minera se constituye por medio de resolución judicial, la cual es otorgada por los Tribunales de Justicia, lo que ha dado suficiente sustento para entender que el procedimiento concesional corresponde a un acto jurisdiccional ${ }^{27}$.

Sin embargo, la posición anterior admite una contraria: entender que el acto por el cual un Tribunal de Justicia otorga una concesión sobre una sustancia concesible, aunque los textos lo llamen "resolución judicial" o "sentencia constitutiva", corresponde, más bien, a un acto administrativo ${ }^{28}$. Como tal, crea derechos subjetivos -que tienen naturaleza de derechos reales administrativos ${ }^{29}$, puesto que se ejercen sobre un bien público- a favor de un concesionario, particularmente, para la exploración o explotación de la riqueza mineral. Al otorgar una concesión, no dirime el juez ningún conflicto entre partes, sino que resuelve sobre la procedencia de una solicitud de un particular para acceder al aprovechamiento de un bien público.

materia, Vergara 2006, 215-244 (argumentando que, por insuficiencia dogmática, el constituyente habla de dominio sobre las minas. Lo correcto es entenderlo como una publificación de la riqueza mineral).

22 Art. 3 LOCCM; Art. 5 CM.

23 No es aplicable a este procedimiento el art. 823 del Código de Procedimiento Civil, de manera que el procedimiento no se transformará en contencioso por la intervención de contendor.

24 Art. 5 LOCCM; Art. 34 CM.

25 En efecto, terceros pueden únicamente participar de este procedimiento en caso de deducir las oposiciones a que se refieren los arts. 61 a 69 CM; el incidente que puede dar origen a dar curso progresivo a los autos del art. $70 \mathrm{CM}$, o la oposición a la constitución de la concesión, según el art. 84 CM.

26 Arts. 86-90 CM. La terminología legal es confusa: la "sentencia constitutiva" realmente es un acto concesional; la "concesión minera", realmente son derechos subjetivos.

27 Vid. Ossa 2013, 319.

28 Se trata de un acto administrativo favorable, esto es, que amplía la esfera del concesionario.

29 Vid. entre otros muchos escritos del autor, Vergara 1989, 473 y ss. 
Esta tesis no es nueva. Ya ha sido postulada hace tiempo por parte de la doctrina minera y administrativa ${ }^{30}$. Lo que ocurre $-y$ que provoca cierta confusión-, es que la Constitución Política ha encargado una tarea administrativa a un órgano que usualmente ejerce funciones jurisdiccionales; cuestión perfectamente posible, como se advierte que órganos distintos a los Tribunales de Justicia están dotados de funciones jurisdiccionales ${ }^{31}$.

Es, por lo demás, consistente en que lo propio de jurisdicción, tal como lo expresan las normas ${ }^{32}$ y la doctrina procesal ${ }^{33}$, es la resolución de los conflictos de intereses de relevancia jurídica entre las partes de un proceso, cuestión que no ocurre en los actos no contenciosos.

No es óbice a esta posición el hecho que el art. 3 de la Ley $N^{\circ} 19.880$ defina los actos administrativos como las decisiones que emitan los órganos de la Administración del Estado ${ }^{34}$. Lo anterior, puesto que esa disposición contiene una definición para los efectos de la aplicación de esa ley, pero no tiene la virtualidad de alterar la naturaleza jurídica de un determinado acto, lo cual viene dado por su sustancia y no por esta declaración formal ${ }^{35}$.

\section{La potencialidad de afectación a los intereses indígenas hace necesaria la consulta y una eventual modificación legislativa}

En principio, el mero otorgamiento por el juez de una concesión minera pudiera no producir una afectación directa en los intereses de una comunidad indígena, pues los derechos que se confieren al concesionario no le permiten inmediatamente el aprovechamiento del terreno superior y el desarrollo de su proyecto minero.

En efecto, la concesión de exploración otorga a su titular el derecho de realizar las labores de exploración (art. $113 \mathrm{CM}$ ), quedando sujeto a: indemnizar los perjuicios que se causen con motivo de la exploración (art. 14

\footnotetext{
30 Desde el punto de vista de la doctrina minera, vid. Vergara 1992, 274 y 293 (postulando que, históricamente, ésta ha sido una función administrativa) y también en (2010) pp. 241-245. En la misma línea ClaUSSEN 2010, 8-9 (quien señala que, por razones históricas y de conveniencia, le fue otorgado al poder judicial y no a la autoridad administrativa la potestad de otorgar los derechos mineros). Desde el punto de vista de la doctrina administrativa, CALDERA 2001, 18.

31 Cea previene que la función jurisdiccional es más amplia que la función judicial, otorgada ésta última a favor de los jueces. CEA 1999, 173.

32 Art. 76 Constitución Política; art. 1 Código Orgánico de Tribunales (COT). El art. 19 N²4 de la Constitución Política, LOCCM o el CM, en ningún pasaje mencionan que los Tribunales de Justicia, al otorgar una concesión minera por medio de resolución judicial, están ejerciendo facultades jurisdiccionales.

33 Vid. por todos, Colombo 1991, 41. El autor indica, además, que es perfectamente posible que Tribunales de Justicia detenten funciones no jurisdiccionales, como es precisamente el caso de los asuntos no contenciosos, en 47.

34 Lo que ha llevado a algunos autores a referir que la ley excluye expresamente la posibilidad de calificar como un acto administrativo a aquellos actos que emanan del poder legislativo o judicial. Vid., Boloña 2005, 32.

35 En este mismo sentido, Vergara 2010, 244-245, aunque dicho autor incluso considera que, por la vía interpretativa, podrán ser aplicables los principios contenidos en la Ley № 19.880.
} 
LOCCM, 14 y $16 \mathrm{~N}^{\circ} 3 \mathrm{CM}$ ); contar con los permisos necesarios en caso de que los terrenos estén cerrados o cultivados (art. 15 y ss. CM); obtener, en su caso, los permisos del art. 17 CM, y respetar las normas sobre policía minera, esto es, las normas contenidas en el Reglamento de Seguridad Minera. El concesionario de exploración tiene la facultad, además, de manifestar con preferencia (art. 114 CM) y el hacerse dueño de las sustancias concesibles que necesite arrancar con motivo de las labores de explotación (art. $113 \mathrm{CM}$ ). Por su parte, la concesión de explotación otorga a su titular el derecho a realizar las labores de exploración y explotación (art. $11 N^{\circ} 1$ LOCCM y 116 inc. $1 \mathrm{CM}$ ), quedando sujeto a las mismas cargas y permisos que la concesión de exploración.

Ahora bien, los derechos que emanan de una concesión minera son, por definición, distintos e independientes de los derechos que tenga el dueño, poseedor o mero tenedor del terreno superficial (art. $19 \mathrm{~N}^{\circ} 24$, inciso $6^{\circ}$ Constitución; arts. 2, 3 y 7 de la LOCCM). Luego, el concesionario podrá, en términos generales, desarrollar las labores de exploración o explotación contando con un título sobre el terreno superficial. El otorgamiento de una concesión minera, entonces, no interfiere directamente con los derechos del propietario superficial, sino que lo posibilitará el posterior acto jurídico que le otorgue algún derecho sobre el terreno.

Con todo, este diseño institucional podría, en algunos supuestos, generar problemas respecto de la protección de los derechos de los pueblos indígenas. Así, la legislación minera permite al concesionario minero -e incluso a cualquier persona- catar o cavar en tierras de cualquier dominio, con la sola restricción que no se trate de terrenos comprendidos por una concesión minera ajena y se trate de terrenos abiertos e incultos (salvo que se obtenga el permiso del art. 15 CM). De igual forma, el concesionario minero podrá solicitar al tribunal la imposición de una servidumbre legal minera para permitir la exploración o explotación de su concesión, lo que permitirá acceso al concesionario al terreno superficial, aun cuando no haya existido consulta en el procedimiento concesional ${ }^{36}$. E incluso en el trámite de constitución se podrán realizar trabajos de reconocimiento de mina, con amparo de la fuerza pública (art. $53 \mathrm{CM}$ ). Por lo demás, no todos los proyectos mineros deben ser sujetos a su evaluación ambiental. Todo lo anterior sin realizarse consulta de ningún tipo ${ }^{37}$.

De manera que, eventualmente, la constitución de una concesión minera podría ser el acto que habilitaría trabajos que podrían producir alguna

\footnotetext{
36 Las autorizaciones medioambientales no son un requisito para el otorgamiento de la servidumbre minera, aunque la jurisprudencia no ha sido clara en la materia. Vid. el análisis de jurisprudencia en Vergara 2016.

${ }_{37}$ No se requerirá una consulta previa a la dictación de la sentencia que constituye la servidumbre, pues, a diferencia de la concesión judicial, su constitución obedece a un acto jurisdiccional. Una posición contraria puede encontrarse en el trabajo de CARMONA 2017. www.elmercurio.com/ Legal/Noticias/Analisis-Juridico/2016/05/30/Las-autorizaciones-urbanisticas-o-medioambientales-no-son-un-requisito-previo-para-la-constitucion-legal-de-servidumbres-mineras.
} 
afectación de los intereses indígenas, lo que ameritaría el proceso de consulta. El problema que aquí surge es que el procedimiento de constitución de una concesión minera no es legalmente apto para identificar una afectación a un interés indígena, ni mucho menos llevar a cabo una consulta. El procedimiento se caracteriza por ser formalizado, con una serie de actos trámite que deben ser cumplidos por el juez y el solicitante, con una total ausencia de discrecionalidad y una mínima intervención de terceros. Recordemos que el art. 34 CM obliga a desarrollar el procedimiento sin intervención decisoria de otra autoridad o persona. No es posible tampoco que el juez ordene, de oficio, la procedencia de una consulta indígena, pues las normas del procedimiento no lo habilitan.

La solución que hoy da el ordenamiento jurídico que regula el aprovechamiento de los minerales al posible conflicto es ex post, derivado de la necesidad de que el concesionario minero indemnice los daños causados, ya sea en virtud de las reglas del derecho común; las especiales contempladas en el art. 14 LOCCM, 14 y $16 \mathrm{~N}^{\circ} 3 \mathrm{CM}$ o las indemnizaciones provenientes de la constitución de la servidumbre legal minera.

Creemos, sin embargo, que lo exigido por el Convenio es lo inverso: busca la consulta de los pueblos indígenas desde las primeras etapas de desarrollo de un proyecto que verse sobre el aprovechamiento de minerales en los territorios indígenas.

\section{Conclusiones}

Las concesiones mineras sobre sustancias concesibles son constituidas en virtud de un acto concesional, que el Código de Minería denomina como "sentencia constitutiva". Dicho acto, al contrario de lo que suele pensarse, constituye una medida administrativa, no jurisdiccional, por lo que las Cortes han errado en la determinación de su verdadera naturaleza. Lo anterior tiene consecuencias para el entendimiento del deber de consulta establecido en el art. 6(1)(a) del Convenio. No puede decirse que toda constitución de un derecho minero deba ser consultado. Se requerirá de un análisis concreto de la posibilidad de que se produzca una afectación directa de los intereses los pueblos indígenas.

Ahora bien, podemos encontrarnos en la situación que el concesionario minero pueda desarrollar su actividad, incluso en tierras indígenas, sin necesidad de una consulta previa ni permiso alguno de la comunidad o persona natural indígena que sea su propietaria. En estos casos podríamos pensar que es necesario que se proceda a la consulta de la concesión minera que otorga tal derecho, en la medida que se produzca alguna afectación concreta a los intereses indígenas. Sin embargo, el procedimiento concesional no es lo suficientemente flexible como para desarrollar este proceso. De manera que una eventual modificación del sistema concesional minero debería tomar en cuenta los compromisos que ha asumido Chile en materia de protección de los derechos indígenas -en especial, a partir del art. 15(2) del Convenio-, 
como también la certeza que es necesaria para que un inversionista deba llevar a cabo un desarrollo minero.

\section{Bibliografía citada}

BAnco Mundial (2005). Operating Policy 4.10. http://siteresources.worldbank.org/OPSMANUAL/Resources/210384-1170795590012/OP4.10.July1.2005.Spanish.pdf.

BARROS, A. y SCHÖNSTEINER, J. (2014). Diligencia debida: proyectos de inversión, propiedad sobre los recursos naturales y consulta libre, previa e informada a los pueblos y comunidades indígenas concernidos. En Instituto Nacional de Derechos Humanos (Coord.), Informe anual sobre derechos humanos en Chile (pp. 203-244). Universidad Diego Portales).

Boloña KelLy, G. (2005). El acto administrativo. LexisNexis.

Caldera Delgado, H. (2001). Tratado de derecho administrativo. Ediciones Parlamento.

Caldera Carmona, C. (2019). El deber de consultar las concesiones y servidumbres mineras: un comentario a la sentencia Rol No 91-2017 (acumuladas 92-2017 y 93-2017) de la Corte de Apelaciones de Copiapó. Revista de derecho (Coquimbo), 26. http://dx.doi. org/10.22199/issn.0718-9753-2019-0019.

Cea Egaña, J. (1999). Teoría del gobierno. Universidad Católica de Chile.

Claussen Calvo, C. (2010). Acerca de la naturaleza jurídica del derecho emanado de la concesión minera. Revista de Derecho de Minas, Aguas y Medio Ambiente (10), 1-34. http:// docplayer.es/1529152-Acerca-de-la-naturaleza-juridica-del-derecho-emanado-de-la-concesion-minera-carlos-claussen-calvo-magister-en-derecho-de-mineria-1.html.

Colombo Campbell, J. (1991). La jurisdicción en el derecho chileno. Editorial Jurídica de Chile.

HeRVÉ, D. y PéREZ, S. (2012). Adecuación de la legislación interna a los estándares impuestos para la administración de los recursos naturales. En J. Contesse (Coord.), El Convenio 169 de la OIT y el derecho chileno (pp. 15-101). Universidad Diego Portales.

International Council of Mining and Metals (ICMM) (2013). Position Statement on Indigenous Peoples. https://www.icmm.com/en-gb/about-us/member-requirements/position-statements/indigenous-peoples.

International Finance Corporation (IFC) (2012). Performance Standard 7. https://www.ifc.org/ wps/wcm/connect/topics_ext_content/ifc_external_corporate_site/sustainability-at-ifc/ policies-standards/performance-standards/ps7.

Kingsbury, B. (April 2011). Indigenous peoples. En Max Planck Encyclopedia of Public International Law. https://opil.ouplaw.com/view/10.1093/law:epil/9780199231690/ law-9780199231690-e948?prd=MPIL.

LiRA Ovalle, L. (2007). Curso de derecho de minería (4a ed.). Editorial Jurídica de Chile.

Montt OYARZún, S. y MATTA AyLWIN, M. (2011). Una visión panorámica al Convenio OIT 169 y su implementación en Chile. Revista de Estudios Públicos (121), 133-212.

NACIONES UnIDAS (2007). Declaración de las Naciones Unidas sobre los Derechos de los Pueblos Indígenas. Recuperado de https://www.un.org/esa/socdev/unpfii/documents/ DRIPS_es.pdf.

Organización Internacional del Trabajo (OIT) (2009). Los derechos de los pueblos indígenas y tribales en la práctica. Una guía sobre el Convenio Num. 169 de la OIT. OIT.

Organización Internacional del Trabajo (OIT) (2013). Informe de Comisión de Expertos en Aplicación de Convenios y Recomendaciones. OIT.

Ossa Bulnes, J. (2013). Tratado de derecho de minería (5a. ed.). Editorial Jurídica de Chile.

SHAW, M. (2014). International Law (7a. ed.). Cambridge University Press.

Stavenhagen, R. (2009). Making the declaration work. En C. Charters y R. Stevanhagen (Eds.), Making the declaration work, the United Nations Declaration on the rights of indigenous peoples (pp. 352-371). IGWIA.

Yañez Fuenzalida, N. (2012). Adecuación de la legislación interna a los estándares impuestos para la administración de los recursos naturales. Comentario de Nancy Yáñez. En J. Contesse (Coord.), El Convenio 169 de la OIT y el derecho chileno (pp. 102-109). Universidad Diego Portales. 
Vergara Blanco, A. (1989). Los derechos mineros como derechos reales administrativos. Revista de Derecho Público, II (115), 473-493.

Vergara Blanco, A. (1992). Principios y sistema del derecho minero. Editorial Jurídica de Chile.

Vergara Blanco, A. (2010). Instituciones de derecho minero. AbeledoPerrot.

Vergara Blanco, A. (30 de mayo de 2016). Las autorizaciones urbanísticas o medioambientales no son un requisito previo para la constitución judicial de servidumbres mineras. El Mercurio Legal. Recuperado de http://www.elmercurio.com/Legal/Noticias/Analisis-Juridico/2016/05/30/Las-autorizaciones-urbanisticas-o-medioambientales-no-son-un-requisito-previo-para-la-constitucion-judicial-de-servidumbres-mineras.aspx.

\section{Normativa citada}

Código de Procedimiento Civil [CPC]. Ley N 1.552 de 1902. 30 de agosto de 1902 (Chile).

Código Orgánico de Tribunales [COT]. Ley N 7.421. 9 de julio 1943.

Constitución Política de la República [Const.]. Decreto No 100 de 2005 [Ministerio Secretaría General de la Presidencia]. 17 de septiembre de 2005.

Ley N 18.097 de 1982. Ley Orgánica Constitucional sobre Concesiones Mineras. 7 de enero de 1982. D.O. $N^{\circ} 31.171$.

Código de Minería [CM]. Ley Nº 18.248 de 1983. 14 de octubre de 1983.

Ley $N^{\circ} 19.300$ de 1994. Aprueba Ley sobre Bases Generales del Medio Ambiente. 1 de marzo de 1994. D.O. N 34.810.

Decreto No132 de 2004 [Ministerio de Minería]. Reglamento de Seguridad Minera. 7 de febrero de 2004.

Decreto No 40 de 2013 [Ministerio del Medio Ambiente]. Aprueba Reglamento del Sistema de Evaluación de Impacto Ambiental. 12 de agosto de 2013.

Decreto No 66 de 2013 [Ministerio de Desarrollo Social]. Aprueba Reglamento que regula el procedimiento de consulta indígena en virtud del artículo $6 \mathrm{~N}^{\circ} 1$ letra a) y $\mathrm{N}^{\circ} 2$ del Convenio $N^{\circ} 169$ de la Organización Internacional del Trabajo y deroga normativa que indica. 15 de noviembre de 2013.

\section{Jurisprudencia citada}

Tribunal Constitucional. Rol 309-00; 4 de agosto de 2000.

Corte Interamericana de Derechos Humanos. Kichwa indigenous people of the Sarayaku Community and its Members v. Ecuador. 27 de junio de 2012.

Corte de Apelaciones de Valdivia. Primera Sala. Rol No 1.091-2014; 23 de abril de 2015.

Corte Suprema. Tercera Sala. Rol No 6.303-2015; 26 de mayo de 2015. 